Het argument, dat het in Amsterdam toegepaste systeem moet leiden tot vermindering van den r'uwen-grondprijs bij aankoop van nieuwe terreinen, achten wij van meer theoretische dan van practische waarde. Schrijver zal moeten toegeven, dat bij onteigening, waarbij de Rechtbank zich door geheel andere beginselen lian laten leiden, beginselen, welke Dr. Delfgaauw scherp onder de loupe neemt, van dit argument mar weinig practisch effect is te verwachten.

Wij moeten onze bespreking hiermede beeindigen, ons es van bewust zijinde, vele door den sehrijver behandelde onderwerpen. waartoe deze veelzijdige materie aanleiding geeft, onbesproken te hebben gelaten. Wij doen dit niet, zonder onze groote wardecring te kennon te geven voor Dr. Delfgaauw's belangrijke studie, warmede de Nederlandsche literatur over de grondpolitiek onzer gemeenten werd verrijkt.

Th. M. GUNDLACH.

\section{REPERTORIUM VAN TIJDSCHRIFT-LITERATUUR OP HET GEBIED VAN ACCOUNTANCY EN BEDRIJFSHUISHOUDKUNDE}

Redactie: Mej. Dr. R. PHILIPS en Drs. G. L. GROENEVELD voor bedrijfseconomie en J. P. DE HAAN en

J. C. SPANGENBERG voor accountancy

\section{A. ACCOUNTANCY}

\section{HET ACCOUNTANTSBEROEP}

An accounting perspective of society

Gat to ne, E. - Schr. bepleit toepassing van de methoden der accountancyleer voor de oplossing van sociale en economische problemen.

A II 2

The Journal of Accountancy October 1934

The future of the C.P.A.

We is sing e r, C. - Voor de accountants zal een steeds grooter en belangrijker arbeidsveld komen, niet als ,auditor" alleen, maar ook als economist en "industrial engineer". $\mathrm{Zij}$ moeten tenslotte niet slechts hun cliënten dienen, maar moeten urachten hun kennis meer ten algemeene nutte aan te wenden.

A II 2

The Journal of Accountancy October 1934

The professional accountant - yesterday, to-day and to-morrow

J o n es, E. F. - Schr. behandelt de huidige positie van den accountant met betrekking tot het verleden en met het oog op de toekomst.

A II 2 The Accountants' Journal November 1931

\section{LEER VAN DE CONTROLE}

Liability of accountants under securities exchange act of 1934

Spencer Gordon, - Bespreekt de op de Securitiesact 1933 toegepaste amendementen, welke veranderingen in de verantwoorderijkheid van den accountant gebracht hebben.

A IV 2

The Journal of Accountancy October 1934

The role of accountancy in the average business

A n n a n, W. - In kleine en middel bedrijuen, waar kostbare machines voor statistiekdoeleinden e.d.g. niet rendabel zjin, kan de accountant bij de inrichting van en de controle op de administratie in velerlei opzicht dit gemis nuttig aanvullen.

A IV 2

The Accountants' Journal October 1934

\section{„A Model Audit"?}

Redactie - Kritiek op de accountantsverklaring in het jaarverslag van "Philips" in het bijzonder betreffende het geven van de omschrijving van de verrichte werkzaamheden, de benoeming door Directie en de genomen aansprakelijkheid voor de voorraden.

A IV 2

The Accountants' Magazine December 1934

\section{B. BEDRIJFSHUISHOUDKUNDE}

\section{a. ALGEMEENE BEDRIJFSHUISHOUDKUNDE}

\section{LEER VAN DEN KOSTPRIJS EN DE PRIJSVORMING}

Uniform accounting for industry

Couchma n, C. B - De interpretaties van wat onder , uniforme" boekhouding moet worden verstaan zijn velerlei. Schrijver zet uitvoerig zijn gedachten over dit onderwerp uiteen, en veroordeelt scherp het pleiten voor uniformiteit alleen ter wille van de uniformiteit zonder dat het verkrijgen van positieve voordeelen vaststaat.

B a IV $2 b$

The Journal of Accountancy November 1934

\section{LEER VAN DE ORGANISATIE}

Overgang naar een stationnair bedrijisleven

$\mathrm{L}$ i ef man $n$, Prof. dr. R. - Wanneer de bevolking afneemt en het internationaal verkeer om politieke redenen aan banden wordt gelegd, komen de landen in den overgang naar een stationnair bedrijfsleven. De vooruitzichten voor een verdere expansie zijn gering. Bijzonder belangrijk is dan het probleem van de verdeeling van de materieele goederen. Alleen een geleidelijke ontwikkeling, uitgaande van of samengaande met een geestelijke evolutie kan de oplossing van dit probleem brengen.

$\mathrm{B}$ a VI 1

Dc Bedrijfseconoom Juli/Aug. 193.4

Les échelons de la distribution: les intermédiaires

P o n thi e re, M. - De tusschenhandel kan in vele gevallen een muttige functie verrichten; de onnutte organen zou men moeten beperken, natuurlijke tendenzen werken hier reeds aan mede.

B a VI 9

L'Organisation September 1934

Les magasins a prix uniques

Rose nthal, A. - (ieeft een korte beschrijving van de geschiede. us van de eenheidsprijzenwinkels, alsmede van hun kenmerken.

B a VI 9

L'Organisation September 1934

De weg tot rationalisatie in overheids-administraties

Mulder, N. - Algemeene beschouwingen en aanduiding van enkele organisatie-problemen.

$\mathrm{B}$ a VI 13

Administratieve Arbeid September 1934

Autocratie en democratie in het beheer der naamlooze vennootschap

M e y, drs. J. L. - In de wetgeving op de naamlooze vennootschap ligt een tegenstrijdigheid: eenerzijds wordt de aansprakelijkheid beperkt tot het bedrag der deelneming, anderzijds is de hoogste mach aan de aandeelhouders voorbehouden. Deze tegenstrijdigheid heeft geleid tot een terugdringen van de macht der aandeelhouders. Schr. schrijft haar ontstaan toe aan de ontwikkeling van het grootbedrijf B a VI 14 De Naamlooze Vennootschap Nov. en Dec. 1934 Quelques conseils sur le chauffage

B lu m e $n$th a l, L. - Beschrijft de werking, de voor-en nadeelen van de centrale verwarming (in het bijzonder van die met heet water). B a VI 19 L'Organisation October 1934

\section{LEER VAN DE ARBEIDSVOORWAARDEN}

Leerlingloonen bij serie- en massafabricage

Le Gué en A peldoorn, --- Dit vervolgartikel behandelt hot leerlingloon bij de toepassing van verschillende loonstelsels.

B a VII 2

Administratieve Arbeid October 1934

Berekening van den onvang der werkloosheid als gevolg van prijsdaling in een gesloten economisch milieu

G o ud ri a a n, Prof. dr. ir. J. - Schr. stelt een aantal formules, op, waaruit hij, in een gesloten economisch milieu, de werkloosheid kan berekenen, die als gevolg van zekere veranderingen in de prijsverhoudingen zal optreden.

B a Vil 10

De Economist Dec. 1931

\section{b. BIJZONDERE BEDRIJVEN}

\section{INDUSTRIE}

Enkele indices aangaande de technische ontwikkeling langs nieuwe wegen in de voornaamste industrieele landen

H a m bu r ger, dr. ir. L. - Schr. onderscheidt een 3-tal vormen van groei en vooruitgang. Statistisch-economisch onderzoek ontbreekt op enkele moderne onderzoekingen na, waarvan schr. een inleidend overzicht geeft.

Schr. gaat dan over tot eigen onderzoek met behulp van octrooicijfers. Schr. concludeert op grond van de Engelsche octrooicijfers dat de gang van den technischen groei langs nieuwe wegen zelve langs lijnen van een groeicurve is blijven groeien. Uit de paralleliteit van octrooicijfers en het product van bevolking en reëel loon in de V. S. concludeert schr. dat de economische beteekenis der octrooicijfers niet moet worden onderschat. Voorts ziet schr. een sprekende paralleliteit tusschen het 9-jaarlijksch voortschrijdend gemiddelde der Britsche octrooicijfers met het reëele volksinkomen uit loonarbeid in Engeland en den monetairen goudvoorraad der wereld. Schr. knoopt hieraan een groot aantal opmerkingen van zeer onderscheiden karakter vast.

$\mathrm{B}$ b V 1 De Economist Nov. en Dec. 1934

De toekomst der vliegtuigindustrie in Nederland

D u $\mathrm{n} l 0 \mathrm{p}, \mathrm{H}$. - Schr. somt een aantal motieven op, die pleiten voor vliegtuigbouw in Nederland. Regeeringssteun zou z.i. verantwoord zijn. $\mathrm{B}$ b V 8 Econ. Statistische Berichten 21 November 1934 
Uit het bedriji van de N.V. Vereenigde Kon. Papierfabrieken der Firma van Gelder en Zonen

Technische beschrijving van het productieproces, verlucht met foto's. B b V 17 Het Cartonnagebedrijf Dec. 1931

De toekomst der gasproductie in Nederland

B ( u y s), J. - Niomenteel staat de toeneming van het gasdebiet vrijwel stil, zoodat men gelegenheid heeft de lijnen van de toekomstige ontwikkeling a tête reposée te bezien. Schr. bespreekt in dit verband de tendenzen tot centrale gasvoorziening, gevallen die daarvan reeds zijn aan te wijzen en eventueele verdere mogelijkheden.

B b V 19

Gasbelangen Dec. 1931

VI. HANDEL

Het vrijwillige filiaalsysteem

Doesscin ate, J. F. ten - Een vrijwillig filiaalbedrijf is een nabootsing van het grootfiliaalbedrijf, waarbij de eigendom gedecentraliseerd blijft, doch de koopkracht der aangeslotenen wordt gecentraliseerd (inkoop in het groot en collectieve verkoop-propaganda). De ontwikkeling in de V.S. was verbazingwekkend. De gedachte heeft ook reeds in de Scandinavische landen en in Nederland post gevat.

$\mathrm{B}$ b VI 4 Econ. Statistische Berichten 17 Oct. 1934

Meervoudige brandverzekering

Pestman, mr. P. D. - Onder meervoudige brandverzekering verstaat schr. de verzekering van hetzelfde voorwerp of vermogensbestanddeel tegen hetzelfde risico bij verschillende verzekeraars. Te onderscheiden zijn de co-assuranties van de cumulatieve assuranties. Bij deze laatste rijst de vraag over de toelaatbaarheid van schadevergoeding, die de verzekerbare waarde overtreft. Schr. geeft een beschouwing van de daaromtrent geldende systemen in de voornaamste West-Europeesche landen, w.o. Nederland (wet, oude en nieuwe contractsbedingen en beurspolissen), waarbij schr, van zijn eigen inzichten over deze materie doet blijken.

$\mathrm{B}$ b IX 3

Het Verzekerings-Archief No. 31934

\section{BOEKEN-REPERTORIUM}

\section{A. ACCOUNTANCY}

\section{ALGEMEEN}

Hosmer, Windsor Arnold, Thomas Henry Sanders and Arthur Warren Hanson. Problems in accounting. New York, 1934.

Picles, W. Key to accountancy. London, 1934.

\section{HET ACCOUNTANTSBEROEP}

Ertel, $H . A$. Aufgaben für das Wirtschaftsprüfer-Examen. Leipzig, 1934

Schigut, Eugen. Kalkulation und Buchfülırung des Bücherrevisors. Berlin, 1934.

\section{LEER VAN DE INRICHTING.}

Bott, Karl. Durchschreibe-Buchführung. Eine systematische Darstellung der Hand- und Maschinen-Durchschreibebuchführung. Hamburg, 1934.

Grier, E. Accounting in the Zenon papyri. New York, 1934

Hosmer, Windsor Arnold, Thomas Henry Sanders and Arthur Warren Hanson. Problems in accounting. New York, 1934.

Janssens, C. H. A. J. Hoofdlijnen der inrichtingsleer. I. Leiden, 1934. Koster, J. De toepassing van machines in de administratie. Purmerend, 1934 .

Manniv, R. L. Accounting for corporations. Boston, 1934.

Picles, W. Key to accountancy. London, 1934.

Roth, Hans. Rationelle Hotel-Betriebsführung. Zürich, 1934.

Schigut, Eugen. Kalkulation und Buchführung des Bücherrevisors. Berlin, 1934.

\section{B. BEDRIJFSHUISHOUDKUNDE}

\section{a. ALGEMEENE BEDRIJFSHUISHOUDKUNDE}

\section{ALGEMEEN}

Todt, Friedrich Wilhelm. Gemeinnutz oder Eigennutz im praktischen Wirtschaftsleben. Hamburg, 1934.

\section{LEER VAN DEN KOSTPRIJS EN DE PRIJSVORMING}

Gelissen, H. en P. M. H. Snel. Economische beginselen bij de kostprijsbepaling en prijsvorming van electrische energie. Maastricht, 1934. Krummel, Paul. Ejkenntnisse über Kalkulationen und Wirtschaftlichkeitsvergleiche. Karlsruhe, 1934.

Wagner, Hermann Wilhelm. Reproduktionskosten-theorie und Lo!nnsteigerung. Frankfurt a.M., 1934.
Zubrod, Hago. Der Teilwertgedanke im Steuerrecht vom Stand-punkte betriebswirtschaftlicher Steuerlehre. Frankfurt am M., 1934.

\section{LEER VAN DE FINANCIERING}

Berry, W. Raising capital. Perthshire,Scotland, 1934.

Casson, H. N. How to buy or borrow. London, 1934.

McGeorge, D. W. Tacking in the stock market. Oakmont, Pa., 1934.

Schneider, Wilh. Allg. Die Finanzierung der mitteldeutschen und Niederlausitzer Braunkohlenindustrie. Herne, 1934.

Stevens, W. M. Financial organization and administration. New York, 1934

Withington, L. Securities exchange act of 1934 analyzed. Boston, 1934

\section{LEER VAN DE ORGANISATIE}

Bolton, J. C. The young salesman's Handbook. London, 1934.

Boston conference on distribution. (Proceedings of the conference). Boston, 1934.

Brendl, Oskar. Wirtschaftliche Konzentrationen, Konjunkturwandel und Krisen. Berlin, 1934.

Buck, G. What's the matter with advertising? Chicago, 1934

Eliasberg, Wiladimir. Lehrbuch der Reklamewissenschaften, auf soziologischer, volkswirtschaftlicher und psychologischer Grundlage. Wien, 1934.

Hall, F. P. Government and business. London, 1934.

Hedges, l. Edward. The advertising of fabricated parts in consuner media. Lawrence, 1934.

Lisowsky, Arthur. Der Unternehmer als Betriebsfaktor. Ein Beitrag zur Lehre von betriebswirtschaftlichen Optimum. Wien, 1934.

Persons, W. M. Government experimentation in business. New York, 1934.

Redlich, Fritz. Reklame, Begriff, Geschichte, Theorie. Stuttgart, 1934. Rosenbloom, J. Ballyhoo, bargains and banners. New York, 1934.

Slavetinsky, Franz. Ist die Rationalisierung schuld an der Krise? Wien, 1934.

Lspohr, Werner. Das Steuergeheinmis. Berlin, 1934

Timar, Margarethe. Das Standortproblem der australischen Industrie. Wien, 1934.

Williams, lohn $\mathrm{H}$. The flexible budget. How to use it to organize, to coordinate, and to stimulatie the activities of executives, as well as to control expense. New York, 1934.

\section{LEER VAN DE ARBEIDSVOORWAARDEN}

Wagner, Hermann Wilhelm. Reproduktionskostentheorie und Lohn. steigerung. Frankfurt a. M., 1934.

\section{b. BIJZONDERE BEDRIJVEN}

\section{EXTRACTIEVE BEDRIJVEN}

Schneider, Wilh. Aug. Die Finanzierung der mitteldeutschen und Niederlausitzer Braunkohlenindustrie. Herne, 1934.

\section{LANDBOUW- EN CULTUURBEDRIJVEN}

Eyken, F. E. Efficiency in den landbouw. Purmerend, 1934.

Freund, Erich. Kautschuk in der Weltwirtschaft. Wien, 1934.

\section{INDUSTRIE}

Gelissen, H. en P. M. H. Snel. Economische beginselen bij de kostprijsbepaling en prijsvorming van electrische energie. Maastricht, 1934. Landry, S. O. Harnessing the power of the press. New Orleans, 1934.

Lehnert, $P$. R. Zur wirtschaftlichen Problematik des technischen Fortschritts, Nürnberg, 1934.

Timar, Margarethe. Das Standortproblem der australischen Industrie. Wien, 1934.

\section{HANDEL}

Boston conference on distribution. (Proceedings of the conference). Boston, 1934.

Carroll, Edward J. Wholesale confectioners' operations. A case study of five firms in Cincinnati, Ohio, Washington, 1934

Gault, Edger H. Performance of department stores, 1933. Ann Arbor, 1934

Mackay, Alexander Leslie Gordon. Business organization and commerce. Oxford, 1934

McDonell. Malcolm A. Wholesale confectionery sales review. Washington, 1934.

\section{TRANSPORT EN ANDERE DIENSTVERLEENING}

Walter $K$. Die Techniek und Wirtschaft der Hygiene im Tierversand bei der Reichsbahn. Berlin, 1934. ,

HOTELS, RESTAURANTS EN ZIEKENHUIZEN

Roth, Hans. Rationelle Hotel-Betriebsfïhrung. Zürich, 1934. 